\title{
Behavioural Observations in Gunn Rats
}

\author{
IVÁN IZQUIERDO* and ROBERT ZAND** \\ Biophysics Research Division, Institute of Science and Technology, University of Michigan, \\ Ann Arbor, Michigan 48105, U.S.A.
}

\begin{abstract}
The Gunn rat is a hooded mutant of albino rat with various biochemical defects, including a low UDP-glucuronosyl-transferase activity. As a consequence, about half of their offspring are jaundiced from birth, due to high free bilirubin levels, and develop widespread brain damage. The behaviour of both jaundiced and nonjaundiced Gunn rats was studied in four different tests in a shuttle-box and in a stepthrough passive avoidance situation, and compared with that of normal hooded rats. No differences among groups were found in performance of shuttle responses to a tone in a pseudoconditioning paradigm
\end{abstract} in which tones and shocks were given at random. However, rats from the two Gunn groups made less shuttlings to the tone in two tests that involved an avoidance contingency (each response cancelled one shock). In addition, nonicteric Gunn rats also performed poorly in a classical conditioning test in the shuttle-box (tones and shocks paired on every trial regardless of responses). This last deficiency of nonicteric Gunn rats may be explained by their higher tendency to freeze in situations involving stimulusstimulus interactions. They also showed a higher latency than that of the two other groups to enter the dark side of the step-through apparatus on their first exposure to it. All animals seemed to learn the passiveavoidance task to the same extent, however, as shown in a retest carried out $48 \mathrm{~h}$ later. Both Gunn groups were hypersensitive to the stereotyped-behaviourinducing action of apomorphine $(0.125-1.0 \mathrm{mg} / \mathrm{kg}$, i.p.), but all groups were about equally sensitive to that of $d$-amphetamine sulfate $(0.5-4.0 \mathrm{mg} / \mathrm{kg})$. Since apomorphine is disposed of by glucuronidation, this might be explained by the low UDP-glucuronosyl-

\footnotetext{
* Visiting professor from the Dept. Biofísica e Fisiologia, Escola Paulista de Medicina, Rua Botucatu 862, 04023 São Paulo, SP, Brasil

** To whom offprint requests should be sent
}

transferase activity known to exist in the Gunn animals. The present results show that additional genetic defects have developed by in-breeding in the Gunn population, which are unrelated to brain damage caused by bilirubin, and which can be well characterized from a behavioural standpoint.

Key words: Gunn rats - Shuttle behaviour - Active avoidance - Passive avoidance - Classical conditioning - Pseudoconditioning - Stereotyped behaviour - Apomorphine - $d$-Amphetamine

The Gunn rat (Gunn, 1938, 1944) is a hooded mutant of normal albino rats, whose offspring divide into two subpopulations, one with about $10 \%$ and the other with about $50 \%$ of normal liver UDP-glucuronosyl-transferase activity (Marniemi et al., 1975). As a consequence, about half of the Gunn offspring are jaundiced from birth, and the other half are not. The former are the animals with the lowest UDP-glucuronosyl-transferase activity (Carbone and Grodsky, 1957; Schmid et al., 1958; Marniemi et al., 1975), in which unconjugated bilirubin levels are very high in both the blood and the various tissues, and in which bilirubin binding to brain areas at an early age causes widespread damage, a condition used as a model for human kernicterus (Blanc, 1961; Sawasaki et al., 1976; Tamaki et al., 1977). Bilirubin binds to, and impairs the function of, various mitochondrial enzymes (Noir et al., 1972); in addition, it binds to histones and to myelin basic protein, and impairs cerebellar protein synthesis (Gurba and Zand, 1974). Among the areas of the brain most affected in jaundiced Gunn rats are the cerebellum (Sawasaki et al., 1976; Tamaki et al., 1977; Zand and Verster, unpublished), and the substantia nigra (Batty and Millhouse, 1976). 
Surprisingly, there are very few behavioural studies on these animals. Tamaki et al. (1977) observed motor deficits in young jaundiced Gunn rats, which subside with age and are attributable to the cerebellar damage. Butcher et al. (1971) reported that jaundiced animals make more errors than their nonjaundiced littermates in a water maze, but they found no difference in openfield behaviour or in an activity cage. In none of these studies, however, were Gunn rats compared with a normal population of hooded rats. This is regrettable, since it is known from the very earliest descriptions (Gunn, 1944) that neither the icteric nor the nonicteric Gunn rats are normal. As was said, both present various degrees of impairment of their glucuronidating and other conjugation enzymes (Marniemi et al,, 1975), and both show diverse alterations of the properties of their red blood cells (Gunn, 1944).

The present paper examines the behaviour of both jaundiced and nonjaundiced Gunn rats, as compared with that of normal hooded animals, in four different shuttle-box situations (Izquierdo, 1976a, b; Izquierdo and Cavalheiro, 1976a, b; Izquierdo and Elisabetsky, 1977; Cavalheiro and Izquierdo, 1977; Calderazzo et al., 1977; Schutz et al., 1977), and in a passive avoidance test (McGaugh and Herz, 1972; Boast et al., 1975), and their performance of stereotyped movements under the influence of apomorphine and of amphetamine (Pijnenburg et al., 1975; Barnett, 1975).

\section{EXPERIMENT I}

Rats in a shuttle-box normally do not perform shuttle responses to a tone or a buzzer (SBs) unless they receive footshocks during the experimental situation (Izquierdo, 1975; Izquierdo and Elisabetsky, 1977). There are at least four buzzer- (or tone-) shock paradigms in which SBs are obtained: (1) the D test, in which buzzers (or tones) and shocks are given at random, and in which SBs develop as a result of nonassociative or 'drive' effects of the shocks (Anisman and Waller, 1973; Izquierdo, 1975) and may therefore be viewed as pseudoconditioned responses (Izquierdo, 1975); (2) the DP test, a classical or Pavlovian conditioning paradigm in which the two stimuli are paired on all trials irrespective of responses, and in which SB performance depends on both the shock-induced drive (D) and the stimulus-stimulus interaction or pairing (P) (Izquierdo, 1976a, b; Izquierdo and Cavalheiro, 1976 b); (3) the DC test, in which the interval between the buzzers or tones and the shocks is varied at random, so that there is no pairing, but in which each SB cancels the next scheduled shock (avoidance contingency, C) (Izquierdo, 1976a,b); (4) the DPC test, or typical two-way avoidance (Izquierdo, 1975), in which the stimuli are paired on every trial, as in DP, but the shocks are omitted every time there is an SB, as in the DC situation. In the DPC test, the three factors, drive (D), pairing $(P)$, and contingency $(C)$, are present (Izquierdo, 1976a, b; Izquierdo and Cavalheiro, 1976 b; Izquierdo and Elisabetsky, 1977).

In a series of previous studies it was shown that $D$, $\mathrm{P}$, and $\mathrm{C}$ are the three main factors in SB behaviour (Izquierdo and Cavalheiro, 1976a, b; Cavalheiro and Izquierdo, 1977; Calderazzo et al., 1977), and that they operate independently from each other (Izquierdo, 1976a, b) and in an additive fashion, so that in a $\mathrm{DP}$ test performance results from $\mathrm{D}+\mathrm{P}$, in a $\mathrm{DC}$ test from $\mathrm{D}+\mathrm{C}$, and in a DPC test from the operation of $\mathrm{D}+\mathrm{P}+\mathrm{C}$ (Izquierdo and Cavalheiro, 1976a, b; Cavalheiro and Izquierdo, 1977; Calderazzo et al., 1977; see Izquierdo and Elisabetsky, 1977). Each of these factors has a pharmacology (Izquierdo, 1976a, b; Izquierdo and Cavalheiro, 1976 b), a maturation rate (Izquierdo and Cavalheiro, 1976a), and a physiological substrate of its own (Cavalheiro and Izquierdo, 1977; Calderazzo et al., 1977; Schutz et al., 1977; Izquierdo and Elisabetsky, 1977). Among such physiological mechanisms, the hippocampus plays an inhibitory role in the operation of $\mathrm{D}$, and a facilitatory role on that of P (Cavalheiro and Izquierdo, 1977; Calderazzo et al., 1977); the ventral portion of the caudate nucleus seems important for both $\mathrm{P}$ and $\mathrm{C}$ (Schutz and Izquierdo, unpublished; see Izquierdo and Elisabetsky, 1977); the pyriform regions has an inhibitory influence on D (Schutz et al., 1977); the central noradrenergic system exerts an inhibitory influence on $\mathrm{P}$ (Izquierdo and Cavalheiro, 1976b); the central dopaminergic system is important for the normal operation of $\mathrm{C}$ (Izquierdo and Cavalheiro, 1976b; Izquierdo and Elisabetsky, 1977); and pharmacologic stimulation of the sympathetic system enhances D and depresses C (Izquierdo, 1974; Izquierdo and Elisabetsky, 1977), whereas that of the parasympathetic system has opposite effects (Izquierdo and Cavalheiro, 1976b).

In the present experiment, the performance of both icteric and nonicteric Gunn rats, and of normal Long Evans hooded rats, was examined in the four tests, D, DP, DC, and DPC.

\section{Materials and Methods}

Subjects. Adult icteric $(160-400 \mathrm{~g})$ and nonicteric $(220-450 \mathrm{~g})$ Gunn rats, and normal hooded Long Evans rats $(230-440 \mathrm{~g})$ were used. Their number appears in Table 1 . The Gunn rats were inbred at the University of Michigan since 1974, from an original group of 6 females and 2 males given to one of us (R.Z.) by Dr. Roger A. Yeary. Icteric Gunn rats were recognized at birth by their yellowish colour (Gunn, 1944), marked, and housed together with their nonicteric littermates. The normal hooded rats were also raised and bred at the University of Michigan. 
Table 1

Performance of shuttle responses to a tone, expressed as \% responses per session, by normal hooded rats and by icteric and nonicteric Gunn rats in four different behavioural tests

Data expressed as means $\pm \mathrm{SE}$. Number of animals in brackets * Significant difference from normal hooded group at $5 \%$ level ** Significant at $1 \%$ level *** Significant difference from icteric Gunn group at $5 \%$ level (Duncan multiple range test; Bliss, 1967)

\begin{tabular}{|c|c|c|c|}
\hline Behavioural test & $\begin{array}{l}\text { Normal hooded } \\
\text { rats }\end{array}$ & $\begin{array}{l}\text { Icteric } \\
\text { Gunn rats }\end{array}$ & $\begin{array}{l}\text { Nonicteric } \\
\text { Gunn rats }\end{array}$ \\
\hline $\mathrm{D}$ & $9.6 \pm 1.4$ & $9.6 \pm 3.4$ & $9.3 \pm 2.3$ \\
\hline DP & $19.1 \pm 2.4$ & $21.0 \pm 3.0$ & $10.3 \pm 2.8(8)^{* * * *}$ \\
\hline DC & $22.3 \pm 2.5$ & $12.0 \pm 2.7(8)^{*}$ & $10.8 \pm 1.2(8)^{* *}$ \\
\hline DPC & $32.2 \pm 4.2(10)$ & $23.6 \pm 2.7(10)^{*}$ & $14.6 \pm 4.0(10)^{* * * * * *}$ \\
\hline$D P-\bar{D}$ & $9.5 \pm 2.4$ & $12.4 \pm 3.5$ & $1.0 \pm 2.8^{* * * * *}$ \\
\hline $\mathrm{DC}-\overline{\mathrm{D}}$ & $12.7 \pm 2.6$ & $2.4 \pm 2.6^{*}$ & $1.5 \pm 2.3^{* *}$ \\
\hline \multicolumn{4}{|l|}{$D+(D P-D)+(D C-D)$} \\
\hline$=\mathrm{D}+\mathrm{P}+\mathrm{C}$ & 31.8 & 24.4 & 11.8 \\
\hline
\end{tabular}

Apparatus. The shuttle-box was $45 \mathrm{~cm}$ long, $20 \mathrm{~cm}$ wide, and $18.5 \mathrm{~cm}$ high. The floor grid consisted of $2 \mathrm{~mm}$ bronze bars spaced $7 \mathrm{~mm}$ apart. There was a $5 \mathrm{~cm}$ high aluminium hurdle at the midline dividing it into two equal compartments. A $60-\mathrm{W}$ lamp $1 \mathrm{~m}$ above the box provided illumination. The acoustic stimulus was a 5-s, $1 \mathrm{kHz}$ tone delivered every $10-40 \mathrm{~s}$ from a $5 \mathrm{~cm}$ o.d. loudspeaker at the midline of the lid of the box. Footshocks were $60 \mathrm{~Hz}, 1.5 \mathrm{~mA}$, scrambled. All animals responded to all footshocks in all tests with shuttling within less than $1, \mathrm{~s}$.

There were several minor but significant differences between this shuttle-box and the one used in previous experiments on $D$, DP, DC, and DPC behaviour (Izquierdo, 1974, 1975, 1976a, b; Izquierdo and Cavalheiro, 1976a,b; Izquierdo and Elisabetsky, 1977; Cavalheiro and Izquierdo, 1977; Calderazzo and Izquierdo, 1977; Schutz et al., 1977). In the present box there was a hurdle at the midline, a tone was used instead of a buzzer, and the dimensions of the box were smaller. As a result of these differences in the present series there were practically no 'jumping' responses (vertical excursion not resulting in a shuttle), whereas these were quite common in the previous experiments (see, for example, Izquierdo, 1976a; Izquierdo and Cavalheiro, 1976b). In the present series, however, the SB performance of normal rats was very similar to that of the normal Wistar rats of the previous papers, as well as to that of a few (2-3 per test) Wistar rats tested in the present box and whose results will not be reported here. Also, in all groups and in all tests, performance of orienting responses to the tone (lateral or upward head movements with or without rearing, sniffing or pricking of the ears; Izquierdo, 1975, 1976a) was very similar to that of orienting responses to the buzzer in the previous papers (72-100\% per session; no differences among groups or among tests in the present series).

Procedure. The four behavioural tests in the shuttle-box were as follows (Izquierdo, 1975, 1976a, b; Izquierdo and Cavalbeiro, 1976a, b; Izquierdo and Elisabetsky, 1977): $D$ test -50 tones were delivered as mentioned above, and 25 shocks were interspersed among them at randomly variable tone-shock intervals of $5-30 \mathrm{~s}$, in random order. Shocks were delivered regardless of whether animals made SBs to any of the previous tones. DP test -50 tones were followed immediately after their offset by footshocks on all trials, irrespective of whether SBs were performed. $D C$ test -50 tones were followed by footshocks at a tone-shock interval that varied randomly between 5 and $30 \mathrm{~s}$ on only those trials in which there were no SBs, in which case the next scheduled shock was cancelled. DPC test-50 tone-shock pairings were made, as in $D P$, but the shock was omitted every time there was an $\mathrm{SB}$, as in $\mathrm{DC}$.
The D factor was estimated directly by measuring SB performance in the $\mathrm{D}$ test. The $\mathrm{P}$ factor was estimated by subtracting from every individual SB performance in the DP test the mean performance of animals of that group in the $D$ test. The $C$ factor was estimated by subtracting from individual $\mathrm{SB}$ performances in the DC test the mean performance of that group in the D test (Cavalheiro and Izquierdo, 1977; Calderazzo et al., 1977; Schutz et al., 1977).

Statistical analysis was by a randomized-group analysis of variance followed by a Duncan multiple-range test (Bliss, 1967).

\section{Results}

Table 1 presents the results.

Nonicteric Gunn rats were inferior to both normal and icteric Gunn rats in SB performance in the DP and DPC tests. In addition, icteric rats were inferior to normal animals in the DC and DPC situations. No differences in SB performance among groups were found in the D test. In the nonicteric Gunn group, no differences in performance could be detected among any of the four tests $(D \cong D P \cong D C \cong D P C)$. No difference in performance of intertrial shuttlings (i.e., those which occurred 'spontaneously' in buzzerbuzzer, buzzer-shock, or shock-buzzer intervals) was observed among groups or among tests (range: 0.3 to 2.3 /session).

In the nonicteric Gunn rats, both DP-D (the $P$ factor) and DC-D (the C factor) were very near zero. In the icteric group, DP-D was as high as in the normal hooded rats, and therefore $P$ presumably was normal; however, in the icteric group DC-D was very close to zero, and therefore the $\mathrm{C}$ factor presumably was absent, as it was in their nonicteric littermates.

In all three groups $D+(D P-D)+D C-D)$ $=\mathrm{D}+\mathrm{P}+\mathrm{C}$ gave a value that was within one standard deviation of the experimentally determined $D P C$ value. This confirms the additive property of $D$, $\mathrm{P}$, and $\mathrm{C}$, which has been observed in 30 groups of animals so far (Izquierdo and Elisabetsky, 1977). 


\section{Discussion}

Both Gunn groups were deficient in shuttle-box learning, even though their performance was normal in the $\mathrm{D}$ or pseudoconditioning test. In nonicteric rats both the $\mathrm{P}$ and the $\mathrm{C}$ factor were absent. In the icteric animals only $\mathrm{C}$ seemed to be lacking. In this respect, icteric Gunn rats closely resembled immature Wistar rats. in which $\mathrm{C}$ is also equal to about zero, and therefore DC and DPC performance is low (lzquierdo and Cavalheiro, 1976a).

Nonicteric Gunn rats do not have any of the widespread brain damage seen in their icteric littermates (Blanc, 1961; Batty and Millhouse, 1976; Sawasaki et al., 1976; Tamaki et al., 1977; Zand and Verster, unpublished). Therefore, it must be concluded that some other genetic defect appeared through in-breeding in this colony, in addition to the one that leads to jaundice and to brain damage in part of the animals. This additional genetic defect was such that it caused a deficient operation of the $\mathrm{C}$ factor in both Gunn groups and, besides, a deficit of the $\mathrm{P}$ factor in nonicteric Gunn animals.

\section{EXPERIMENT II}

Shuttling is not a normal component of a rat's response to a tone or a buzzer (Izquierdo, 1975), and in order to perform an SB a rat must overcome its more natural tendency to freeze (Anisman and Waller, 1973; Anisman, 1975; Izquierdo and Elisabetsky, 1977). This may be done through the operation of $\mathrm{D}, \mathrm{P}$, or $\mathrm{C}$. The importance of $\mathrm{P}$ in solving the conflict between freezing and shuttling in favor of the latter is quite obvious in a DP test, in which the animals get shocked every time they shuttle, a fact that should presumably work in favor of the tendency to freeze (Izquierdo and Cavalheiro, 1976 b; Izquierdo and Elisabetsky, 1977).

The only difference between icteric and nonicteric Gunn rats in Experiment I was the apparent absence of the $\mathrm{P}$ factor in the nonicteric animals, which led to their very low performance in the DP and DPC tests. One possibility is that these animals had such a high tendency to freeze in these tests that $\mathbf{P}$ was unable to overcome it. If this were so, then nonicteric Gunn rats should also show a high tendency to freeze in other behavioural situations that involve stimulus pairings. Step-through passive avoidance (McGaugh and Herz, 1972; Boast et al., 1975) is a paradigm in which, on their first exposure to the apparatus, animals must relate two stimuli (the light in the small compartment and the darkness of the larger one) in order to enter the dark side of the box following their natural drive to it. A freezing animal will tend to remain longer in the lighted side than one with a higher tendency to shuttle. In a retest session, this latency suffers an addi- tional and major influence of retention processes (McGaugh and Herz, 1972), and this is the reason why passive avoidance retests are so popular in memory research (McGaugh and Herz, 1972; Boast et al., 1975; Izquierdo and Elisabetsky, 1977).

This experiment examines step-through passive avoidance in the same animals that were used in Experiment I.

\section{Materials and Methods}

Subjects. They were the same as in Experiment I, after 3-5 days of rest.

Apparatus. The same box was used as in Experiment $\mathrm{I}$, after very thorough cleaning. A $32 \times 20 \times 18 \mathrm{~cm}$ cardboard box was slid into the shuttle-box after withdrawal of the aluminium hurdle, and so the box was divided into two unequal compartments: a smaller one outside the cardboard box, which was illuminated by a $100 \mathrm{~W}$ lamp $1 \mathrm{~m}$ above it, and a larger compartment, which was dark. A $5 \times 7 \mathrm{~cm}$ hole at the middle of the limiting wall connected the two compartments.

Rats were placed in the lighted side, held gently by their trunk, tranversal to the hole and with their nose touching the acrylic wall to the left of it. The moment the animals touched the grid of the safe compartment with their four paws, a time counter was activated and latency to shuttle into the dark side was counted. When the rats entered the dark side and had their four paws in it, a $1.5 \mathrm{~mA}$ footshock was set on and maintained until the animals returned through the hole into the lighted side. All animals were submitted to two such sessions with a 48-h interval between the two. The first will be called 'exposure session,' and the second one, 'retest session.' Latency to enter the dark side on the retest session, minus latency on the exposure session, was used as a measure of retention (McGaugh and Herz, 1972; Boast et al., 1975). A ceiling equal to first day's latency plus $300 \mathrm{~s}$ was imposed on all animals for the retest. All rats except 3 in each group reached this ceiling.

Statistical comparisons were as in Experiment I.

\section{Results}

Table 2 presents the results.

Nonicteric Gunn rats had a much longer latency to shuttle into the dark side on exposure day than the animals from the other two groups. There was no difference in this parameter between icteric Gunn and normal hooded rats. The latency of these two groups, by the way, was very similar to that of Wistar albino animals submitted to a similar apparatus $(20.0 \pm 6.3 \mathrm{~s}$, $N=9$; unpublished data from the first author's laboratory in São Paulo).

In addition, the behaviour of nonicteric Gunn rats during their residence in the lighted compartment on exposure session was quite different from that of the two other groups. Nonicteric Gunn rats remained quiet most of the time, which may be defined as freezing, and then they eventually shuttled quite abruptly through the hole. Icteric and normal rats, on the other hand, spent their time exploring and 
Table 2. Latency to enter the dark compartment of a step-through passive avoidance apparatus, in $\mathrm{s}$, on the exposure session (day 1), and on a retest session (day 2) minus the exposure session

\begin{tabular}{|c|c|c|}
\hline Group & $\begin{array}{l}\text { Latency } \\
\text { on exposure session } \\
\text { (day 1) }\end{array}$ & $\begin{array}{l}\text { Latency on retest } \\
\text { session minus } \\
\text { latency on exposure } \\
\text { session } \\
\text { (day } 2 \text { - day } 1 \text { ) }\end{array}$ \\
\hline Normal hooded & $27.4 \pm 11.2(13)$ & $218.2 \pm 40.9(13)$ \\
\hline Icteric Gunn & $22.4 \pm 8.0(14)$ & $223.9 \pm 31.0(14)$ \\
\hline Nonicteric Gunn & $61.4 \pm 14.0(19)^{*}$ & $252.6 \pm 27.0$ \\
\hline
\end{tabular}

Data expressed as means \pm SE. Number of animals in brackets * Significant difference from the two other groups at $5 \%$ level in a Duncan multiple range test (Bliss, 1967)

sniffing around, and entered through the hole in the course of such activity.

All three groups showed a similar degree of retention of this task on the retest session. Again, this was similar to I.I.'s unpublished data for normal Wistar albino rats $(253.7 \pm 49.6 \mathrm{~s}, N=9)$.

\section{Discussion}

Since all animals learned this task quite well, the low performance of the Gunn rats in the shuttle-box tasks of Experiment I cannot be attributed to any general learning inability. In particular, it can not be attributed to an impossibility of mastering avoidance contingencies, but, instead, to a specific deficiency of the active avoidance contingency factor $\mathrm{C}$. It should be noted that in the passive task the avoidance contingency (shuttle-shock) was opposite to that of Experiment I (no shuttle-shock); and, by virtue of the natural tendency of this species to freeze, it was possibly easier to learn (see Anisman and Waller, 1973). In fact, passive avoidance is learned in one trial, whereas shuttle avoidance, DC or DPC, requires many more.

The longer latency to shuttle of nonicteric Gunn rats on the exposure session in this experiment may be attributed to an increased tendency to freeze when confronted with the light-dark interface. Therefore it seems possible that these rats have some general tendency of that sort in situations which require a stimulus-stimulus interaction, and that this may be the explanation for their apparent lack of a $\mathrm{P}$ factor in the tests of Experiment I.

\section{EXPERIMENT III}

In previous papers the $\mathrm{C}$ factor of shuttle avoidance was shown to depend on the function of central dopaminergic systems (Izquierdo and Cavalheiro,
Table 3. Incidence of stereotyped behaviour in rats treated with apomorphine or with $d$-amphetamine sulfate

A. Apomorphine

\begin{tabular}{lllll}
\hline Group & \multicolumn{4}{l}{ Dose $(\mathrm{mg} / \mathrm{kg})$} \\
\cline { 2 - 5 } & 0.125 & 0.25 & 0.5 & 1.0 \\
\hline Normal hooded & - & $0 / 5$ & $2 / 8$ & $6 / 6$ \\
Icteric Gunn & $2 / 5$ & $3 / 4$ & $7 / 7$ & - \\
Nonicteric Gunn & $2 / 5$ & $4 / 6$ & $5 / 5$ & - \\
\hline
\end{tabular}

B. $d$-Amphetamine sulfate

\begin{tabular}{lllll}
\hline Group & \multicolumn{2}{l}{ Dose $(\mathrm{mg} / \mathrm{kg})$} \\
\cline { 2 - 5 } & 0.5 & 1.0 & 2.0 & 4.0 \\
\hline Normal hooded & $5 / 8$ & $4 / 5$ & $5 / 5$ & $5 / 5$ \\
Icteric Gunn & $4 / 6$ & $5 / 7$ & $4 / 4$ & $4 / 4$ \\
Nonicteric Gunn & $4 / 6$ & $4 / 6$ & $5 / 5$ & $5 / 5$ \\
\hline
\end{tabular}

Data expressed as number of rats showing stereotyped behaviour (see text)/total number of rats tested with that dose of the drug

1976b). A very simple way to verify the functioning of such systems is to investigate the sensitivity of rats to the stereotyped behaviour-inducing effect of apomorphine and amphetamine. Apomorphine stimulates dopamine receptors, and amphetamine releases endogenous dopamine (Barnett, 1975). In situations in which the endogenous dopamine content is low, animals become insensitive to amphetamine (Creese and Iversen, 1972), and hypersensitive to apomorphine (Barnett, 1975; Herman et al., 1976).

The present experiments investigate the induction of stereotyped behaviour (Creese and Iversen, 1972; Pijnenburg et al.,1975) by various doses of apomorphine and of amphetamine in the same rats of Experiments I and II.

\section{Materials and Methods}

Subjects. The same as in Experiments I and II.

Procedure. Apomorphine $(0.125,0.25,0.5$, and $1.0 \mathrm{mg} / \mathrm{kg})$, and $d$-amphetamine sulfate $(0.5,1.0,2.0$, and $4.0 \mathrm{mg} / \mathrm{kg})$ were given i.p., and then the animals were kept in their home cages and watched for the appearance of stereotyped behaviour as defined by Pijnenburg et al. (1975). Rats treated with apomorphine were observed every $5 \mathrm{~min}$ for $45 \mathrm{~min}$, and those treated with amphetamine every $15 \mathrm{~min}$ for $75-90 \mathrm{~min}$. Stereotyped behaviour was considered to be one of the following: (1) continuous sniffing with fast repetitive head and/or foreleg movements, with or without occasional bursts of licking, gnawing, and biting, and with periods of high locomotor activity; (2) continuous licking, gnawing or biting with fast repetitive head and/or foreleg movements while remaining in the same place of the cage (Pijnenburg et al., 1975). In all groups the animals treated with the higher doses of the drugs reached level (1), and those treated with the lower doses seldom surpassed level (1). 


\section{Results}

Table 3 presents the results.

Both icteric and nonicteric Gunn rats were more sensitive to this effect of apomorphine than normal hooded rats. All groups were about equally sensitive to amphetamine.

\section{Discussion}

The results did not fulfill the prediction based on the hypothesis that Gunn rats would have a low endogenous dopamine content, since they were as sensitive to amphetamine as were normal rats.

The hypersensitivity of Gunn rats to apomorphine may easily be explained by the low UDP-glucuronosyltransferase activity known to exist in both icteric and nonicteric animals of this strain (Marniemi et al., 1975). Apomorphine, a diphenol, is known to be disposed of largely through glucuronidation. Since Gunn rats have a deficient glucuronidating mechanism, they should be more sensitive to this and related compounds.

\section{GENERAL DISCUSSION}

The data from Experiments I and II show that in circumstances that require operation of a $\mathrm{P}$ factor (Izquierdo, 1976a,b; Izquierdo and Cavalheiro, 1976 b; Izquierdo and Elisabetsky, 1977), any condition that will enhance the animals' tendency to freeze will result in an impairment of active behaviours, such as shuttling. Nonicteric Gunn rats seem to have just such an increased tendency to freeze in situations that require a stimulus-stimulus association (the DP and DPC tests of Experiment I, and the exposure session of Experiment II), this being their main behavioural difference with their icteric littermates. In addition, all Gunn rats, icteric and nonicteric, lack a normal operation of the $\mathrm{C}$ factor of active avoidance behaviour (shuttle-no shock), whereas both seem to learn quite well avoidance contingencies of an opposite sign (no shuttle-no shock).

These behavioural deficits are obviously unrelated to the brain damage caused by bilirubin, since there is no such damage in nonicteric Gunn rats (Blanc, 1961; Sawasaki et al.,1976; Tamaki et al., 1977; Zand and Verster, unpublished). It must be concluded, therefore, that the in-breeding procedure led to other genetic defects in the Gunn strain, in addition to the one for which these animals were originally bred. These additional defects may be quite clearly defined in behavioural terms. It is possible that they do not occur in all the Gunn colonies around the world, since the genetic constitution of such colonies may be different (Dutton, 1971).
On the other hand, the high sensitivity of Gunn rats to apomorphine-induced stereotypy may be explained quite readily by the genetic defect for which this strain was bred, namely, low UDP-glucuronosyltransferase activity (Carbone and Grodsky, 1957; Schmid et al., 1958; Marniemi et al., 1975). This defect, however, occurs in all animals of this strain, albeit to a different degree (Marniemi et al., 1975), whereas only half of them develop jaundice and brain lesions (Blanc, 1961).

The genetic and biochemical constitution of the Gunn rat therefore appears to be quite complex; and future experiments with these animals should avoid the oversimplifications that have been too common in the past (cf. all papers in which all defects are attributed to impaired glucuronidation, and all papers which expect to find behavioural or other nervous disturbances exclusively in the icteric littermates). It should also be borne in mind that genetic complexities may be a rule, rather than the exception, in most rat populations that have been closely in-bred for a long time.

Acknowledgements. Supported by NIH Grant 5R01-NS11923-02 to R.Z. We thank Dr. Otto Z. Sellinger, of the Mental Health Research Institute of the University of Michigan, for having kindly provided laboratory facilities, and Dr. Floris DeB. Verster, of the same institution, for his invaluable help in setting up the apparatuses used in the present experiments.

\section{REFERENCES}

Anisman, H.: Time-dependent variations in aversively motivated behaviors: non-associative effects of cholinergic and catecholaminergic activity. Psychol. Rev. 82, 359-385 (1975)

Anisman, H., Waller, T. G.: Effects of inescapable shock on subsequent avoidance performance: role of response repertoire changes. Behav. Biol. 9, 331-355 (1973)

Barnett, A.: Dopamine receptors and their role in brain function. In: Current developments in psychopharmacology, vol. 1, W. B. Essman and L. Valzelli, eds., pp. 1-35. New York: Spectrum 1975

Batty, H. K., Miilhouse, O. E.: Ultrastructure of the Gunn rat substantia nigra. I. Cytoplasmic changes. Acta Neuropathol. (Berl.) 35, 93-107 (1976)

Blanc, W. A.: Kernicterus in Gunn's strain of rats. In: Kernicterus, A. Sass-Kortsák, ed., pp. 150-152. Toronto: Univ. Toronto Press 1961

Bliss, C. I.: Statistics in biỏlogy, vol. 1. New York: McGraw-Hill 1967

Boast, C. A., Zornetzer, S. F., Hamrick, M. R.: Electrolytic lesions of various hippocampal subfields in the mouse: differential effects on short- and long-term memory. Behav. Biol. 14, 85-94 (1975)

Butcher, R. E., Stutz, R. M., Berry, H. K.: Behavioral abnormalities in rats with neonatal jaundice. Am. J. Ment. Deficiency 75 $755-759$ (1971)

Calderazzo $F^{o}$, L. S., Moschovakis, A., Izquierdo, I. : Effect of hippocampal lesions on rat shuttle responses in four different behavioral tests. Physiol. Behav. (in press, 1977) 
Carbone, J. V., Grodsky, G. M.: Constitutional nonhemolytic hyperbilirubinemia in the rat. Defect of bilirubin conjugation. Proc. Soc. Exp. Biol. Med. 94, 461 - 463 (1957)

Cavalheiro, E. A., Izquierdo, I.: The effect of hippocampal and of neocortical spreading depression on rat shuttle behavior in four different experimental paradigms. Physiol. Behav. (in press, 1977)

Creese, I., Iversen, S. D.: Amphetamine response in rat after dopamine neurone destruction. Nature New Biol. 238, 247-248 (1972)

Dutton, G. J.: Glucuronide-forming enzymes. In: Handbook of experimental pharmacology, B. B. Brodie and J. M. Gillette, eds., vol. 28, pp. 378-400. Berlin-Heidelberg-New York: Springer 1971

Gunn, C. K.: Hereditary acholuric jaundice in a new mutant strain of rats. J. Heredity 29, 137-139 (1938)

Gunn, C. K.: Hereditary acholuric jaundice in the rat. Can. Med. Assoc. J. 50, 230-237 (1944)

Gurba, P. E., Zand, R. : Bilirubin binding to myelin basic protein, histones and its inhibition in vitro of cerebellar protein synthesis. Biochem. Biophys. Res. Commun. 58, 1142-1147 (1974)

Herman, Z. S., Brus, R., Drybański, A., Szkilnik, R., StomińskaZurek, J.: Influence of 6-hydroxydopamine on the behavioral effects induced by apomorphine or clonidine in rats. Psychopharmacology 50, 73-80 (1976)

Izquierdo, I.: Possible peripheral adrenergic and cholinergic mechanisms in pseudoconditioning. Psychopharmacologia (Berl.) 35, $189-193(1974)$

Izquierdo, I.: Relations between orienting, pseudoconditioned and conditioned responses in the shuttle-box - a pharmacological analysis by means of LSD and dibenzamine. Behav. Biol. 15, $193-205(1975)$

Izquierdo, I.: A pharmacological separation of buzzer-shock pairing and of the shuttle-shock contingency as factors in the elicitation of shuttle responses to a buzzer in rats. Behav. Biol. 18, $75-87$ (1976a)

Izquierdo, I.: Stimulus pairing and the response-reinforcement contingency as separate factors in shuttle behavior: the effect of anticonvulsant drugs. Ciencia e Cult. (São Paulo) 28, 1334- 1337 (1976b)

Izquierdo, I., Cavalheiro, E. A.: The influence of stimulus pairing and of the shuttle-shock contingency on the performance of shuttle responses to a buzzer by weanling rats. Behav. Biol. 17, $119-122(1976 a)$

Izquierdo, I., Cavalheiro, E. A.: Three main factors in rat shuttle behavior: their pharmacology and sequential entry in operation during a two-way avoidance session. Psychopharmacology 49, $145-157(1976 b)$

Izquierdo, I, Elisabetsky, E.: Pharmacological and physiological dissection of the main factors in shuttle behaviour. Acquisition and long-term memory. In: IBRO symposium on brain mechanisms in learning and memory, M. A. B. Brazier, ed.; IBRO Monograph Series, vol. 4. New York: Raven (in press, 1977)

Marniemi, J., Vainio, H., Parkki, M.: Drug conjugation in Gunn rats: reduced UDP-glucuronosyl transferase and UDP-glucosyl transferase activities with increased glycine- $\mathrm{N}$-acyltransferase activity. Pharmacology 13, 492-501 (1975)

McGaugh, J. L., Herz, M. J.: Memory consolidation. San Francisco: Albion 1972

Noir, B. A., Boveris, A., Garaza Pereira, A. M., Stoppani, A. O. M.: Bilirubin: a multi-site inhibitor of mitochondrial respiration. FEBS Lett. 27, 270-274 (1972)

Pijnenburg, A. J. J., Honig, W. M. M., Van Rossum, J. M.: Antagonism of apomorphine and $d$-amphetamine-induced stereotyped behaviour by injection of low doses of haloperidol into the caudate nucleus and the nucleus accumbens. Psychopharmacologia (Berl.) 45, 65-71 (1975)

Sawasaki, Y., Yamada, N., Nakajima, H.: Developmental features of cerebellar hypoplasia and brain bilirubin levels in a mutant (Gunn) rat with hereditary hyperbilirubinemia. J. Neurochem. 27, 577-583 (1976)

Schmid, R., Axelrod, J., Hammaker, L., Swarm, R.: Congenital jaundice in rats due to a defect in glucuronide formation. J. Clin. Invest. 37, 1123-1130 (1958)

Schutz, R. A., Nasello, A. G., Izquierdo, I. : Effect of lesions of the anterior amygdala-pyriform cortex region on rat shuttle behavior in four different experimental paradigms. Ciencia e Cult. (São Paulo) (in press, 1977)

Tamaki, Y., Semba, R., Tooyama, S.: Cerebellar hypoplasia and motor development in congenitally jaundiced Gunn rats. Physiol. Behav. 18, 255-259 (1977)

Received July 28, 1977 